NIPER-611

Distribution Category UC-122

CT Imaging of Enhanced Oil Recovery Experiments

NIPER--611

Topical Report

DE93 000103

By

Bonnie L. Gall

December 1992

Work Performed Under Cooperative Agreement No. DE-FC22-83FE60149

Prepared for

U.S. Department of Energy

Assistant Secretary for Fossil Energy

Jerry Casteel, Project Manager

Bartlesville Project Office

P. O. Box 1398

Bartlesville, OK 74005

Prepared by

IIT Research Institute

National Institute for Petroleum and Energy Research

P.O. Box 2128

Bartlesville, OK 74005

WMTER

ro 


\section{TABLE OF CONTENTS}

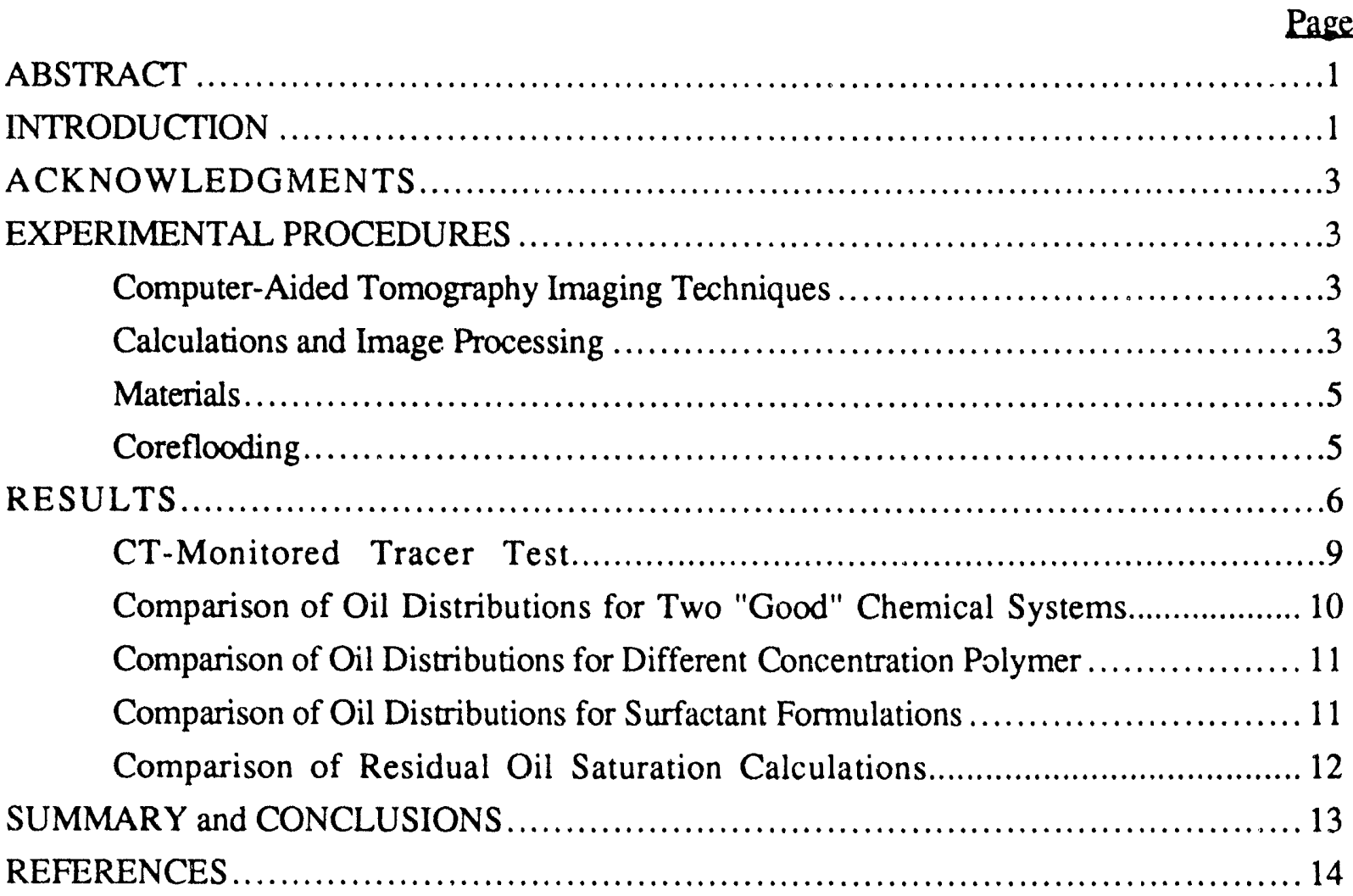

\section{TABLES}

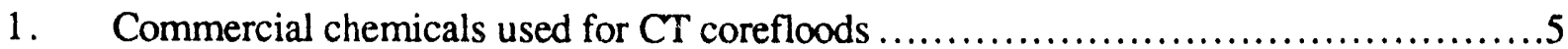

2. Oils used in CT-monitored corefloods ...........................................6

3. Summary of coreflooding procedures.............................................

4. Fluid compositions and core permeabilities for the four CT corefloods ...............8

5. Summary of CT coreflood objectives ..........................................9

6. Comparison of average oil saturations at various stages of a chemical flood............ 13

\section{ILLUSTRATIONS}

1. CT density of NBU oil as a function of the amount of added iododecane............ 15

2. Comparison of CT density scale and porosity scale, coreflood CT-CF 3........... 15

3. Composite CT image along core for tracer test, CT-CF $4 \ldots \ldots \ldots \ldots \ldots \ldots \ldots \ldots \ldots \ldots$

4. Horizontal composite CT images for tracer test, CT-CF 4 ...................... 17

5. CT images after surfactant injection for CT-CF 1 and CT-CF $4 \ldots \ldots \ldots \ldots \ldots \ldots \ldots \ldots$

6. CT images after polymer injection for CT-CF 1 and CT-CF 4 ......................... 19

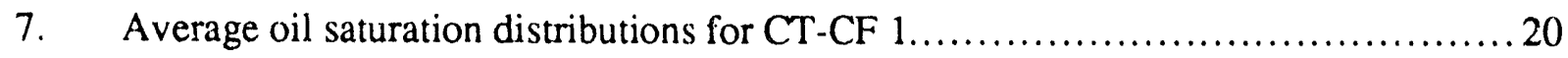

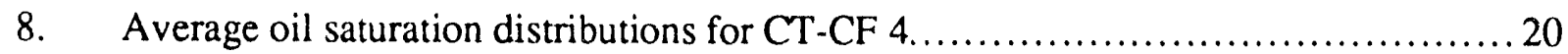




\section{ILLUSTRATIONS - Continued}

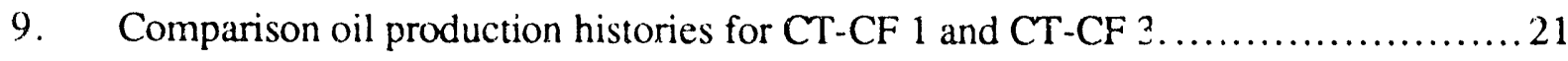

i0. Composite CT images of CT-CF 3 after surfactant injection and polymer injection..... 22

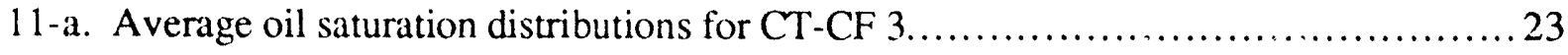

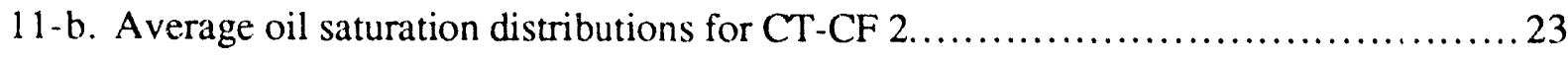

12. Composite CT images of CT-CF 2 after surfactant injection and polymer injection.... 24

13. CT image of oil saturation distributions near the core exit for CT-CF $2 \ldots \ldots \ldots \ldots \ldots .25$

14. Comparison of CT images of oil saturation distributions for CT-CF 2 and CT-CF 4. 26 


\title{
CT Imaging of Surfactant-Enhanced Oil Recovery Experiments
}

\author{
by Bonnie L. Gall
}

\begin{abstract}
$\mathrm{X}$-ray computerized tomography (CT) has been used to study fluid distributions during chemical enhanced oil recovery experiments. Four CT-monitored corefloods were conducted, and oil saturation distributions were calculated at various stages of the experiments. Results suggested that this technique could add significant information toward interpretation and evaluation of surfactant/polymer EOR recovery methods.

CT-monitored tracer tests provided information about flow properties in the core samples. Non uniform fluid advance could be observed, even in core that appeared uniform by visual inspection. Porosity distribution maps based on CT density calculations also showed the presence of different porosity layers that affected fluid movement through the cores.

Several types of CT-monitored corefloods were conducted. Comparisons were made for CT-monitored corefloods using chemical systems that were highly successful in reducing residual oil saturations in laboratory experiments and less successful systems. Changes were made in surfactant formulation and in concentration of the mobility control polymer. Use of a poor mobility control agent failed to move oil that was not initially displaced by the injected surfactant solution; even when a "good" surfactant system was used. Use of a less favorable surfactant system with adequate mobility control could produce as much oil as the use of a good surfactant system with inadequate mobility control. The role of mobility control, therefore, becomes a critical parameter for successful application of chemical EOR. Continuation of efforts to use CT imaging in connection with chemical EOR evaluations is recommended.
\end{abstract}

\section{INTRODUCTION}

$\mathrm{X}$-ray computerized tomography $(\mathrm{CT})$ is a technique that generates cross-sectional images of objects from a series of $\mathrm{X}$-ray attenuation measurements produced as the $\mathrm{X}$-ray source rotates around the object of interest. At NIPER, significant effort over the past several years has resulted in the development and use of CT imaging tecliniques to characterize rock structure and fluid distributions within the rock pore space. This type of information is useful in many applications of interest in the oil and gas industry. Information concerning the development of techniques and principles of operation of CT imaging can be found elsewhere. ${ }^{1.3}$ This report will summarize 
initial efforts to use CT imaging techniques to help understand and evaluate fluid movement and oil production during surfactant/polymer enhanced oil recovery experiments.

This work is part of a DOE sponsored research project, Improvements in Surfactant Flooding Methods (Project BE4A), to improve chemical EOR flooding methods. Overall objectives of this project are (1) to apply advance EOR technology based on mixed surfactant systems to improve oil recovery from Class 1 reservoirs; (2) to extend the use of surfactant EOR to different salinity and temperature ranges by developing surfactant systems which are more adaptable to changes in chemical composition in selected reservoirs; (3) to develop cost-effective chemical system for selected field application that may contain low concentrations of synthetic surfactant and alkaline additives. CT studies were performed under task 3 to help evaluate the role of mobility control and core permeability on oil recovery.

Evaluation of the effectiveness of chemical systems to mobilize oil is a complex process. The ability of the surfactant to solubilize oil depends on the chemical nature of the surfactant and the oil and other experimental parameters such as brine salinity and temperature. Measurements of solution properties such as interfacial tension, solubilization parameters, and phase behavior are used to screen surfactant formulations to determine conditions under which they can effectively solubilize oil. Ultimately, however, the chemical formulation must be injected into rock samples to test its ability to mobilize discontinuously distributed oil droplets, generate an oil bank, and keep the oil bank mobilized to maximize oil production. In the past, oil production during laboratory tests was monitored using pressure measurements along the core length and by collecting fluids exiting from the core. By watching pressure fluctuations as the fluid fronts advance, average advance of an oil bank can be observed. No information, however, is obtained for non uniform fluid distributions during the recovery experiments using these techniques. CT imaging, however, allows visualization of fluid movement during various stages of an oil recovery experiment. Observation of non uniform saturation distributions that result from core heterogeneities (permeability streaks) or from problems in fluid mobilization (poor chemical design) may help improve design or application criteria for chemical EOR technology.

Four surfactant/polymer corefloods have been conducted using CT imaging in conjunction with effluent fluid collection to monitor oil saturations during various stages of chemical floods. Several parameters were varied for these tests including core permeability, surfactant formulation/oil optimization, and polymer mobility effectiveness. This report will briefly describe these experiments, compare results of oil recovery, and illustrate how visualization of oil saturations using CT imaging can help evaluate process effectiveness. 


\section{ACKNOWLEDGMENT}

This work was sponsored by the U. S. Department of Energy under cooperative agreement DE-FC22-83FE60149. The author wishes to thank Liviu Tomutsa and Alan Brinkmeyer of the NIPER CT Imaging Group for their expertise, advice, and assistance while conducting these experiments. Appreciation is also expressed to Larry Scott of NIPER and Rohit Baktha and Michael Hankinson, Associated Western University (AWU) summer students, for their assistance in performing the experiments.

\section{EXPERIMENTAL PROCEDURES}

\section{Computer-Aided Tomography Imaging Techniques}

The CT equipment and general operating procedures at NIPER have been developed and described previously. ${ }^{1}$ A Siemens Somatron II CT scanner was used to image the dry and fluidsaturated cores in the high resolution mode of $125 \mathrm{kV}$ and $460 \mathrm{mAs}$. Each scan produced an image 256 by 256 volume elements (voxels) that represented a volume of $0.5 \mathrm{~mm}$ by $0.5 \mathrm{~mm}$ by either 4 or $8-\mathrm{mm}$, depending on the slice thickness selected. The images were stored temporarily on the CT scanner hard disk and then transferred to other computer storage for further examination or data manipulation. The data transfer program, CT_Capture Apl, was developed under the NIPER BE12 imaging project.

To determine porosity and fluid saturations, it is important that each scan be conducted on the same area of the core under the same scanning conditions. To l,elp achieve these objectives, a computer-controlled positioning Table has been constructed and installed under the BE12 project. This allows the core to be repositioned in the beam within $0.012 \mathrm{~mm} .{ }^{4}$ In addition, since the $\mathrm{X}$ ray source operates by rotating around the object being scanned, two consecutive images are slightly displaced. To avoid errors caused by non alignment of images taken during different stages of the coreflood, it is important to capture all odd-numbered images as the X-ray tube rotates in one direction and all even-numbered images as it rotates in the other direction.

\section{Calculations and Image Processing}

After X-ray scanning of a core, the produced images are stored for further viewing and analysis to determine porosity and two-phase fluid saturation distributions. First, the individual image files can be merged to produce one file for 3-D image analysis. The program, CT_Merge Apl, was written by the Imaging Group for this application. A commercial software package, trademark SPYGLASS, developed by the National Center for Supercomputer Applications, 
University of Illinois, is then used for data display and analysis. Any 3D object can be rotated and sliced for viewing along any of the $\mathrm{XY}, \mathrm{XZ}$, and $\mathrm{YZ}$ planes through the object.

The methods to calculate porosity and two-phase fluid saturation distributions have been described previously.! A program written by the NIPER Imaging Group, CT_PorSat Apl, calculates the porosity and saturation values for each pixel of an image from values determined during the CT scan of the dry core, the brine-saturated core, and a core containing both aqueous and oil phases.

The porosity-saturation calculation requires CT values for the various fluids used in the tests. The instrument is calibrated such that the CT value for air is -500 . The CT values of the other fluids used in these experiments were measured by filling small vials with liquid, placing the vials in holes drilled in core samples to approximate attenuating characteristics of the consolidated samples, and measuring CT values of the fluids. This procedure results in measurement of CT values for pixels that are completely filled with the fluid of interest.

For untagged brine without alkaline additives, the average CT value was 23 . The CT value of brine containing alkaline additives was approximately 50 . Oil was tagged with iododecane to increase the CT density of the sample. Figure 1 shows the correlation between $C T$ value and amount of iododecane added to samples of North Burbank Unit (NBU) oil. Some variation in CT density can be observed for vials located near the outer edge of the rock and near the middle of the sample. At the present time, the porosity-saturation calculations are not programmed to vary the CT value of the fluid depending on location in the core. This is one area of improvement that may be investigated in the future.

The saturation distributions generated using the porosity-saturation program produce the same images that are generated by subtracting a dry scan of the core from any saturated scan. The scale, however, is converted from CT densities to fractional values representing open pore space in the rock (in the case of single fluid saturation) or relative amounts of oil or brine (in the case of two fluid saturation). Figure 2 shows an example of images generated by the two calculation methods. The u'pper image in Fig. 2 shows a direct subtraction (pixel by pixel) of the dry scan from the brine saturated scan for one slice from the CT-CF 3 experir.ient, and the lower image is generated by the porosity-saturation calculation program.

Average saturations for any slice or portion of any slice are calculated with the aid of additional purchased software, DIP (Digital Image Processing) Station ${ }^{\mathrm{TM}}$ from Hayden Image Processing Group (HIPG). 


\section{Materials}

Chemicals used in this study are identified in Table 1:

For the first three CT coreflood experiments, cores were initially saturated with a simulated reservoir brine containing $1.02 \% \mathrm{NaCl}, 0.39 \% \mathrm{CaCl}_{2}$, and $0.33 \% \mathrm{MgCl}_{2}$. (Salt concentrations are reported as weight to weight.) For the fourth test, the core plug was saturated with the same brine used to formulate the surfactant mixture, $0.9 \% \mathrm{NaCl}$.

Two oils, both from Class 1 reservoirs, have been used for CT-coreflooding experiments. Their properties differed significantly from each other, as shown in Table 2; however, to visualize oil saturation using the CT, the sils were tagged with approximately $20 \%$ iododecane. This affected the viscosity of the Hepler oil more than that of NBU oil. All viscosity values reported were measured at ambient temperature.

\section{Coreflooding}

Coreflooding procedures used for these tests have also been described previously. ${ }^{5} \mathrm{~A}$ general outline of the steps involved in conducting coreflood experiments is shown in Table 3. Berea sandstone core plugs $(3.8-\mathrm{cm}$ diameter, $21-$ to $27-\mathrm{cm}$ length) that ranged in liquid permeability from 150 to $500 \mathrm{mD}$ were encased in epoxy and scanned dry. The dry scan is very important because it is used in all the calculations to obtain porosity and fluid saturation maps of the core. Cores were then evacuated, saturated with carbon dioxide (two cycles), and then saturated with degassed brine (composition determined by conditions of the experiment). The brine-saturated cores were then scanned. At this point, it is recommended that a tracer test be conducted to define and confirm the presence of heterogeneities in the core that will affect fluid flow. Of the four CT-monitored corefloods conducted to date, only one core has been

TABLE 1. - Commercial chemicals used for CT corefloods

\begin{tabular}{cccc}
\hline Chemical type & Company & Tradename & Activity, wt \% \\
\hline $\begin{array}{c}\text { Mixed anionic } \\
\text { surfactant } \\
\text { alkyl aryl }\end{array}$ & Stepan & B-105 & 51.4 \\
$\begin{array}{c}\text { sulfonate } \\
\text { petroleum } \\
\text { sulfonate }\end{array}$ & Stepan & B-110 & 48.3 \\
$\begin{array}{c}\text { Xarthan gum, } \\
\text { biopolymer }\end{array}$ & Witco & TRS 10-410 & 62.0 \\
\hline
\end{tabular}


TABLE 2. - Oils used in CT-monitored corefloods

\begin{tabular}{ccccc}
\hline $\begin{array}{c}\text { Field } \\
\text { (oil name) }\end{array}$ & State & Gravity, ${ }^{\circ}$ API & $\begin{array}{r}\text { Viscosity, } \\
\mathbf{2 3}^{\circ} \mathbf{C}\end{array}$ & $\begin{array}{c}\text { Viscosity of } \\
\text { tagged oil, cP }\end{array}$ \\
\hline Hepler & Kansas & 26.1 & 76 & 38 \\
N. Burbank Unit & Oklahoma & 39.5 & 8.6 & 8 \\
\hline
\end{tabular}

preevaluated using a tagged brine solution $(10 \% \mathrm{NaI})$.

The cores were then flooded with tagged oil (crude oil containing approximately $20 \%$ iododecane) to residual water saturation followed by brine to residual oil saturation. CT scans were conducted after each of these steps. Finally, the surfactant and polymer slugs were injected siquentially. CT scans were taken after injection of the surfactant, after part of the polymer slug injection (for two of four tests), and after the injection of at least one pore volume of polymer. Cumulative oil production was also measured as a function of fluid through the core.

Table 4 summarizes fluid compositions and core permeabilities for the four tests. All floods were conducted in Berea sandstone core at ambient temperature.

\section{RESULTS}

The objectives of using CT imaging in connection with traditional coreflood experiments were to provide more detailed understanding of fluid movement during the flood and fluid saturation distributions at various stages of fluid injection. CT imaging might provide more detailed answers to such typical questions as: Does the surfactant formulation mobilize oil? Is an oil bank formed? Can core heterogeneities be ubserved and how do they affect oil front movement? Can trapped oil be observed? How do different injection strategies affect oil movement and overall oil recovery?

Four CT monitored corefloods have been conducted, and oil saturation distributions have been calculated at various stages of the experiments. Results suggest that this technique can add signiticant information toward interpretation and evaluation of surfactant/polymer EOR recovery methods. These tests were conducted using chemical formulation and injection strate gies that had been evaluated for oil recovery efficiency previously. 5,6 Table 5 summarizes initial objectives of the CT corefloods and anticipated comparisons between tests. 
TABLE 3. - Summary of CT coreflood operations

\begin{tabular}{|c|c|c|c|}
\hline $\begin{array}{c}\text { Experimental } \\
\text { operation }\end{array}$ & Measurement & Calculation & CT scan \\
\hline $\begin{array}{l}\text { Select, trim, clean } \\
\text { (as required) } \\
\text { and dry core }\end{array}$ & $\begin{array}{l}\text { Measure core dimensions } \\
\text { Save trimmed ends, mark } \\
\text { orientation and send pieces } \\
\text { for thin section and/or } \\
\text { XRD }\end{array}$ & & Scan dry core \\
\hline $\begin{array}{l}\text { Encase core in } \\
\text { epoxy with endpieces } \\
\text { Pressurize with } \mathrm{CO}_{2} \\
\text { and test for leaks } \\
\text { (about } 30 \text { psi) }\end{array}$ & Measure dry weight & & \\
\hline $\begin{array}{l}\text { Evaculate, saturate with } \\
\mathrm{CO}_{2} \text { ( } 2 \text { cycles), saturate } \\
\text { with degassed brine }\end{array}$ & $\begin{array}{l}\text { Measure saturated } \\
\text { weight }\end{array}$ & Calcuiate pore volume & Scan saturated core \\
\hline $\begin{array}{l}\text { Conduct tracer test } \\
\text { with } 10 \% \text { Nal brine }\end{array}$ & & & $\begin{array}{l}\text { Scan with time as } \\
\text { tracer moves through } \\
\text { core }\end{array}$ \\
\hline $\begin{array}{l}\text { Flow tagged oil to } \\
\text { residual brine } \\
\text { saturation }\end{array}$ & Measure brine out & $\begin{array}{l}\text { Calculate oil saturation } \\
\text { at residual water sat. }\end{array}$ & $\begin{array}{l}\text { Scan oil- } \\
\text { saturated core }\end{array}$ \\
\hline $\begin{array}{l}\text { Waterflood to residual oil } \\
\text { saturation }\end{array}$ & Measure oil out & $\begin{array}{l}\text { Calculate residual oil } \\
\text { saturation }\end{array}$ & $\begin{array}{l}\text { Scan waterflooded } \\
\text { core }\end{array}$ \\
\hline \multirow[t]{2}{*}{$\begin{array}{l}\text { Inject chemicals } \\
\text { preflush } \\
\text { surfactant } \\
\text { polymer } \\
\text { etc., as needed }\end{array}$} & $\begin{array}{l}\text { Measure oil and } \\
\text { brine production }\end{array}$ & $\begin{array}{l}\text { Calculate: Pore volume, } \\
\text { oil cut, changes in residual } \\
\text { oil. accumulated oil production, } \\
\text { etc. }\end{array}$ & $\begin{array}{l}\text { Scan several times as } \\
\text { needed to monitor oil } \\
\text { advance }\end{array}$ \\
\hline & $\begin{array}{l}\text { Analytical measurements } \\
\text { on effluent samples, as } \\
\text { needed: viscosity, pH, } \\
\text { surfactant concentration, } \\
\text { etc. }\end{array}$ & $\begin{array}{l}\text { Calculate values from } \\
\text { measurements }\end{array}$ & \\
\hline
\end{tabular}




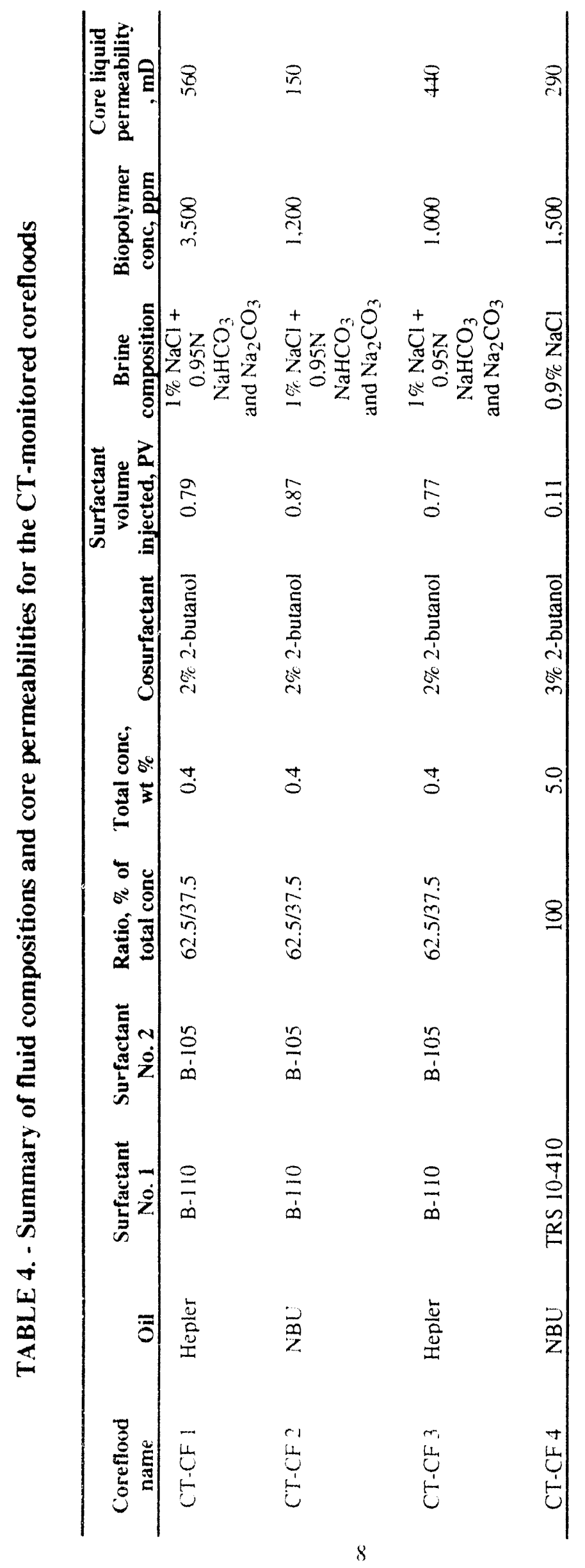




\section{TABLE 5. - Summary of CT corefloods objectives and anticipated areas of comparison}

\begin{tabular}{lll}
\hline Coreflood identification & \multicolumn{1}{c}{ Coreflood objectives } & \multicolumn{1}{c}{ Comments } \\
\hline CT-CF 1 and CT-CF 4 & $\begin{array}{l}\text { Conduct oil recovery with "good" } \\
\text { chemical system for Hepler and } \\
\text { NBU oils, respectively }\end{array}$ & $\begin{array}{l}\text { Oil recovery greater than 80\% } \\
\text { of residual oil after waterflood. } \\
\text { Tracer test for CT-CF 4 }\end{array}$ \\
CT-CF 2 & $\begin{array}{ll}\text { Chemical system less effective } \\
\text { for NBU oil. }\end{array}$ & $\begin{array}{l}\text { Compare with results from } \\
\text { CT-CF 4 }\end{array}$ \\
CT-CF 3 & $\begin{array}{l}\text { Same surfactant system for } \\
\text { Hepler oil but less effective } \\
\text { mobility contro! polymer conc. }\end{array}$ & $\begin{array}{l}\text { Compare with resuits from } \\
\text { CT-CF 1 }\end{array}$ \\
\hline
\end{tabular}

\section{CT-monitored Coreflood}

Initially, surfactant/polymer CT coreflood experiments were conducted without first injecting a tracer to determine if fluid advance was affected by core heterogeneities. Porosity distribution calculations for the first three tests indicated that different porosity layers existed in both higher and lower permeability core plugs. A tracer test was conducted for CT-CF 4 . The average permeability for this sample was approximately $280 \mathrm{mD}$. This sample was cut from the same Berea sandstone block as that used for CT-CF 2 (average permeability of $150 \mathrm{mD}$ ). Sevcral bedding layers could be seen parallel to the direction of flow in the CT-CF 2 sample. These visible layers could not be seen in sample CT-CF 4; however, they were evident in the CT images of the dry core.

For the tracer test, a 0.2 -PV slug of $10 \%$ sodium iodide was injected at an average linear flow rate of $10 \mathrm{ft} / \mathrm{day}$. The bedding planes were oriented horizontally. Figure 3 shows a vertical composite CT image along the core length that visualizes the fluid front and trailing edge part way through the injection. The effect of differences in permeability of the layers can clearly be observed. Composite horizontal slices at various positions in the core, as indicated, are shown in Fig. 4. The fluid fronts within a layer resemble those for fluid flow in a pipe, indicating relatively uniform rock properties within a layer.

The porosity distribution, as calculated from the CT scans of the dry and brine saturated core, indicated the existence of these layers, as shown in Fig. 4 for CT-CF 4 . The tracer test 
images confirm the sontinuity and connectivity of the layers in this sample and provide greater contrast to delineate layers than are shown in the porosity images.

Based on the images from these preliminary studies, tracer tests are recommended for previously untested rock samples but may become redundant for samples that are closely associated with ones that have already been characterized.

\section{Comparison of Oil Distributions for Two "Good" Chemical Systems}

Previous experimental studies had already demonstrated that the surfactant/polymer systems designed for Hepler and NBU oils, as summarized in Table 2, recovered $80 \%$ or more of the residual oil remaining after waterflood in laboratory corefloods. Figures 5 and 6 show representative CT composite images of CT-CF 1 and CT-CF 4, respectively, after surfactant injection and after polymer injection. In both cases, the surfactant slug has penetrated the core more rapidly along one layer or area of the core which corresponds to an area of higher porosity.

Both cases also showed an area of higher oil saturation ahead of the surfactant slug (oil bank). The oil bank can be seen more clearly for CT-CF 1 . These differences may be "real" or may be related to differences in experimental procedures. For example, CT-CF 1 was scanned using a 4-mm slice width, whereas CT-CF 4 used a $8-\mathrm{mm}$ slice width. Averaging over different area sizes may affect the relative magnitude of saturation contrasts. Also a slightly greater amount of iododecane was added in CT-CF 1 . However, the factors affecting the amount and appearance of the oil saturation increase are still under investigation.

After polymer injection, oil saturations were very low throughout the core. Average oil distributions for each CT slice after surfactant injection and polymer injection are shown in Fig. 7 for CT-CF 1 and Fig. 8 for CT-CF 4. Very little oil was left near the core inlet in both cases. Average oil saturation was also low near the core exit. However, the oil near the core exit was more heterogeneously distributed than that near the inlet, indicating that the chemical had the tendency to channel through some of the layers more than through others. Use of longer cores or a reduction in the amount of chemicals injected would accentuate this effect.

Researchers in the past have concluded that laboratory tests using relatively short core plugs overestimates recovery efficiencies. Use of CT imaging may allow improved interpretation of chemical flooding methods using relatively short core samples. This is one area of suggested future research. 


\section{Comparison of Oil Distributions for Different Concentrations of Mobility Control Polymers}

Coreflood CT-CF 3 was a repeat of CT-CF 1 except for the use of lower concentration mobility control polymer. In this case, average oil saturation distributions after surfactant injection are similar. However, use of a less effective mobility control agent failed to move any additional oil from the exit end of the core. Oil saturations in this region remained at the same level as those determined after the waterflood. Total oil production histories for the two tests are shown in Fig. 9.

Both lests showed that the surfactant injection was non uniform with at least one area in both cores that was more permeable to injected fluids. Figure 10 shows CT composite images after surfactant injection and after polymer injection for CT-CF 3. These images should be compared with the images for CT-CF 1 shown in Figs. 7 and 8. Average oil saturations after various stages of fluid injection are shown in Fig. 11-a. The chemicals failed to affect the oil saturations in the second hali of the core. Fluid channeling was significant for the lower concentration polymer, resulting in lower overall oil production. Therefore, the CT images indicate that bypassing of oil by the injected chemicals is a major effect of inadequate mobility control design.

\section{Comparison of Oil Saturation Distributions for Different Surfactant Formulations}

Previous studies had shown that a mixed surfactant system designed for Hepler oil was less successful when used to mobilize NBU oil..$^{5}$ CT-CF 2 was conducted to visualize oil saturation distributions using this chemical formulation. Figure 11-b shows average oil saturations after the surfactant injection and after the polymer injection for this test. Corresponding composite CT images of the core are shown in Fig. 12. In this view, the oil appears to be fairly well swept in this vertical plane after polymer injection although there is some indication that the fluids have channeled through the center and upper areas of the core. Figure 13 shows a cross section near the core exit. Lowest oil saturations (in the upper left-hand quadrant) ranged from 15 to $28 \%$ while saturations in other areas ranged from 44 to $58 \%$. These high saturations suggested that, in these areas, the waterflood was fairly ineffective and the chemicals failed to significantly change flow properties. Average oil saturations were reduced along the whole length of the core, however. This was in contrast to the case where inadequate mobility control was used (CT-CF 3), and average oil saturations near the core exit were not reduced from those observed after the waterflood (see Fig. 10). 
A comparison can be made between tests CT-CF 2 and CT-CF 4 to evaluate the relative effectiveness of two different surfactant systems that were used with NBU oil. Figure 14 shows oil saturation distributions near the core entrance after the chemical flood for each test. The mixed surfactant system (B-105 and B-110) used for CT-CF 2 left a higher oil saturation near the core entrance than the petroleum sulfonate system used for CT-CF 4 (average saturation values were $10 \%$ for CT-CF 2 and $3.9 \%$ for CT-CF 4). Significantly larger areas showed little or no oil saturation for CT-CF 4 than for CT-CF 2.

Lower IFT values that are generated between oil and water using the petroleum sulfonate system than those using the mixed surfactant system may be the major contributing factor. The IFT values for the petroleum sulfonate and mixed surfactant systems with NBU oil were 0.001 and $\mathrm{C} .014 \mathrm{mN} / \mathrm{m}$, respectively. The average saturations generated by the mixed surfactant system with Hepler oil (IFT $=0.008 \mathrm{mN} / \mathrm{m}$ for tests CT-CF 1 and CT-CF 3) were approximately 5 to $6 \%$. Additional studies will continue to evaluate whether initial oil mobilization effectiveness as observed by CT imaging techniques can be correlated with solution properties such as IFT values and phase behavior measurements.

Both the level and distribution of oil saturation near the core entrance as provided by CT imaging techniques provide some information on the relative efficiency of the chemicals used for the EOR process. The experiments that have been conducted to date will provide a baseline for comparison and further evaluation of the usefulness of CT imaging to investigate factors affecting chemical EOR effectiveness.

\section{Comparison of Residual Oil Saturation from Volumetric and CT Imaging Calculations}

Average residual oil saturations for the core sample can be calculated from a material balance of oil introduced into the core versus oil produced during the various stages of the coreflood and from the CT density measurements. Residual oil saturation values are shown in Table 6. Reasonable agreement was obtained for these values for all four corefloods discussed in this report. Closer agreement may result if CT saturation calculations incorporate CT density distribution values for the oil and aqueous solutions that vary with position in the core. (Refer to Fig. 1, for example.) In addition, slight differences in CT density values of injected aqueous solutions are not taken into account for this study. In almost all cases, average oil suturation values were higher from the CT calculations than those from the volumetric measurements. Sensitivity of oil saturation measurements to variations in fluid CT density is an area for further investigation. 
TABLE 6. - Comparison of average oil saturations at various stages of a chemical flood

\begin{tabular}{clcc}
\hline $\begin{array}{c}\text { Coreflood } \\
\text { identification }\end{array}$ & Flood operation & $\begin{array}{c}\text { S }_{\text {or }} \text { from } \\
\% \text { PV }\end{array}$ & $\begin{array}{c}S_{\text {or }} \text { from } \\
\text { volumetric, \% PV }\end{array}$ \\
\hline CT-CF 1 & Waterflood & 39 & 36 \\
& Surfactant injection & 35 & 34 \\
& Polymer injection & 8 & 6 \\
CT-CF 2 & Waterflood & 43 & 43 \\
& Surfactant injection & 35 & 37 \\
& Polymer injection & 27 & 27 \\
CT-CF 3 & Waterflood & 39 & 35 \\
& Surfactant injection & 35 & 33 \\
& Polymer injection & 27 & 22 \\
CT-CF 4 & Waterflood & 39 & 36 \\
& Surfactant injection & 33 & 30 \\
& Polymer injection & 6 & 0 \\
\hline
\end{tabular}

\section{SUMMARY AND CONCLUSIONS}

Four surfactant/polymer corefloods have been conducted in conjunction with CT-imaging of oil saturations. These tests provide a baseline for comparison for additional tests designed to examine the effect of chemical and core properties on oil recovery efficiency. Two tests examined oil saturation changes for surfactant systems known to provide high oil recovery in laboratory tests using two different oils. A third test altered the concentration of the mobility control polymer to provide unfavorable mobility. The fourth test examined oil mobilization using a surfactant formulation that was less effective in producing oil. All these tests were conducted in Berea sandstone cores at ambient temperature. The cores appeared to have at least some layers which varied in porosity and permeability.

The CT imaging of "good" surfactant systems indicated that fluid fronts could advance in a non uniform manner so that a higher proportion of chemicals was injected into the high r porosity layers. At the end of these tests, average oil saturation was low but non homogeneous throughout the core.

Use of a poor mobility control agent failed to move oil that was not initially displaced by the injected surfactant solution; even when a "good" surfactant system was used. Use of a less 
favorable surfactant system with adequate mobility control could produce as much oil as the use of a good surfactant system with inadequate mobility control. The role of mobility control, therefore, becomes a critical parameter for successful application of chemical EOR.

Reasonable agreement was obtained between residual oil saturations calculated from CT measurements and from volumetric measurements of oil produced.

The effect of core heterogeneities on the chemical movement and oil production during chemical EOR can be examined simultaneously with the evaluation of chemical formulation effectiveness using CT imaging techniques.

It is recommended that the use of CT imaging techniques be continued in connection with investigations of chemical EOR applications. Possible research areas include use of reservoir rock with known pore systems and mineralogy, computer simulation of fluid movement based on CT imaging results, as well as evaluation of effects of chemical formulation on oil production.

\section{REFERENCES}

1. Tomutsa, L., D. Doughty, S. Mahmood, A. Brinkmeyer, and M. Madden. Imaging Techniques Applied to the Study of Fluids in Porous Media. Dept. of Energy Report No. NIPER-485, August, 1990.

2. Morgan, C. L. Principles of Computed Tomography. University Park Press, Baltimore, $\mathrm{MD}, 1983$.

3. Wellington, S. L., and H. J. Vinegar. X-ray Computerized Tomography. J. Pet. Tech., Aug. 1987, pp. 885-898.

4. Tomutsa, L., D. Doughty, A. Brinkmeyer, and S. Mahmood. Imaging Techniques Applied to the Study of Fluids in Porous Media. Dept. of Energy Report No. NIPER-582, February, 1992.

5. Llave, F. M., B. L. Gall, T. R. French, L. A. Noll, and S. M. Munden. Phase Behavior and Oil Recovery investigations using Mixed and Alkaline-Enhanced Surfactant Systems. U. S. Dept. of Energy Report - NIPER-567, December 1991.

6. Boneau, D. F., and R. L. Campitt. A Surfactant System for the oil-wet Sandstone of the North Burbank Unit. J. Pet. Tech., May, 1977, pp. 501-506. 


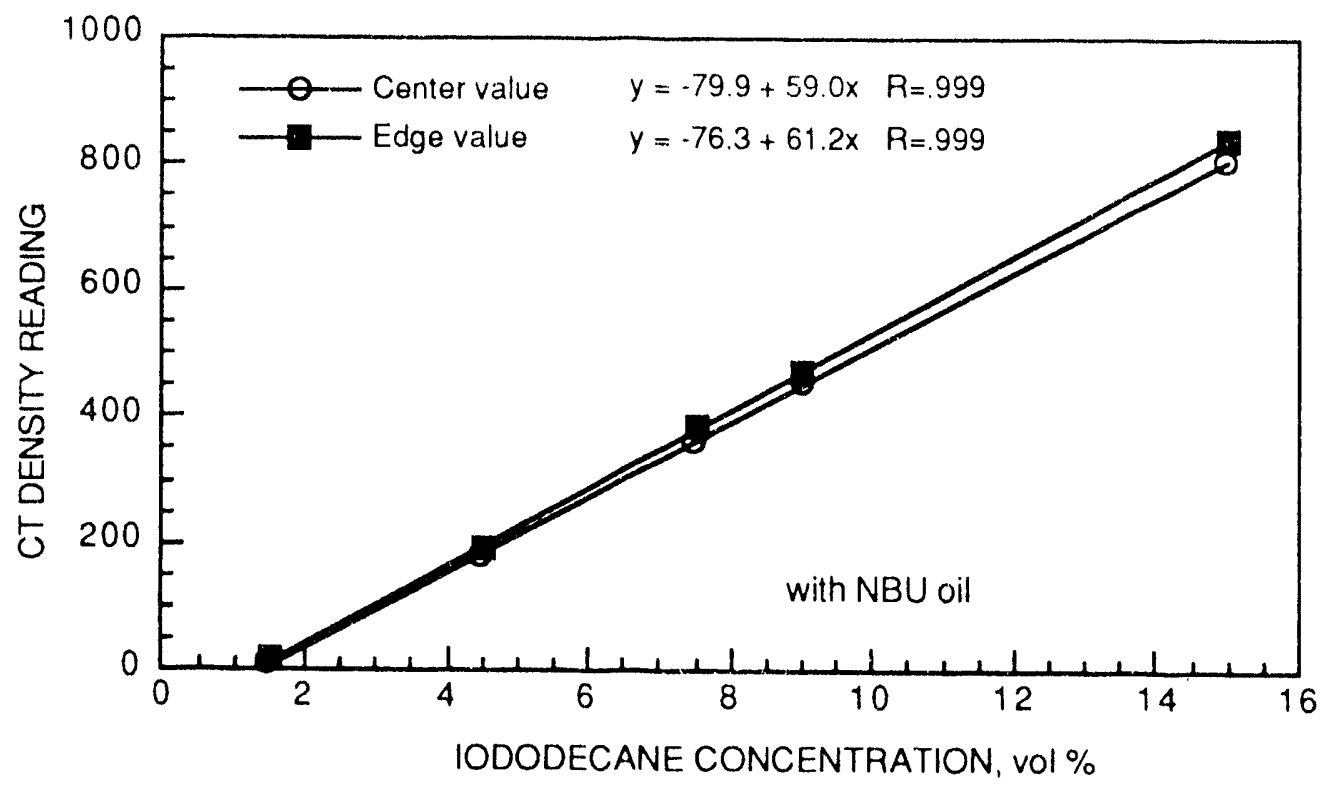

FIGURE 1. CT density of NBU oil as a function of the amount of added iododecane. CT density is affected by amount of rock X-ray must pass through.

CT. C'F 3

Brine Dry
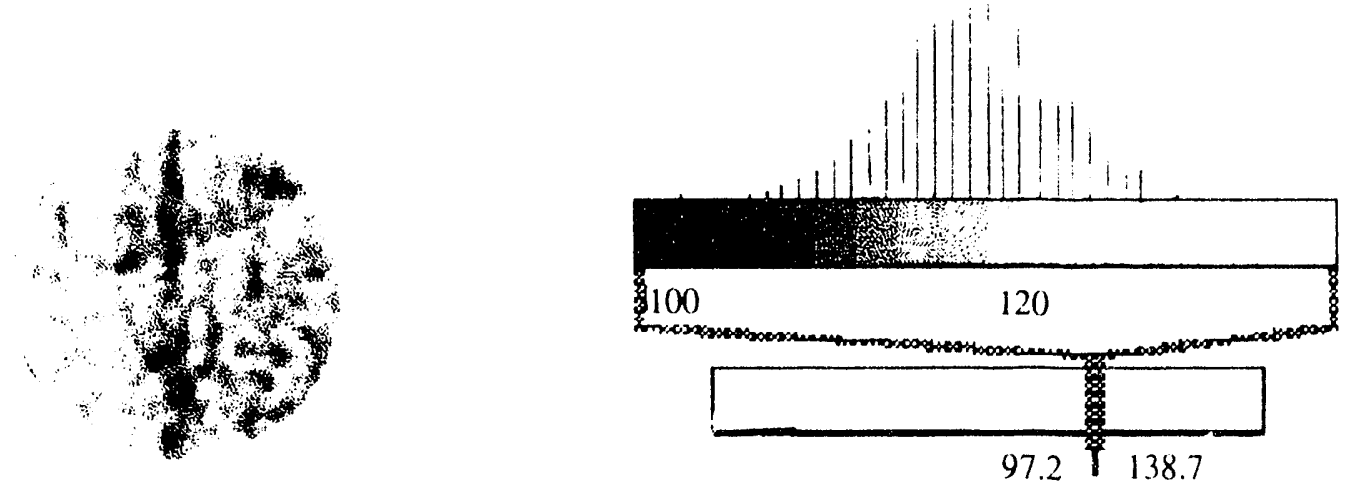

C'T. C 3

Porosity

Silice 32
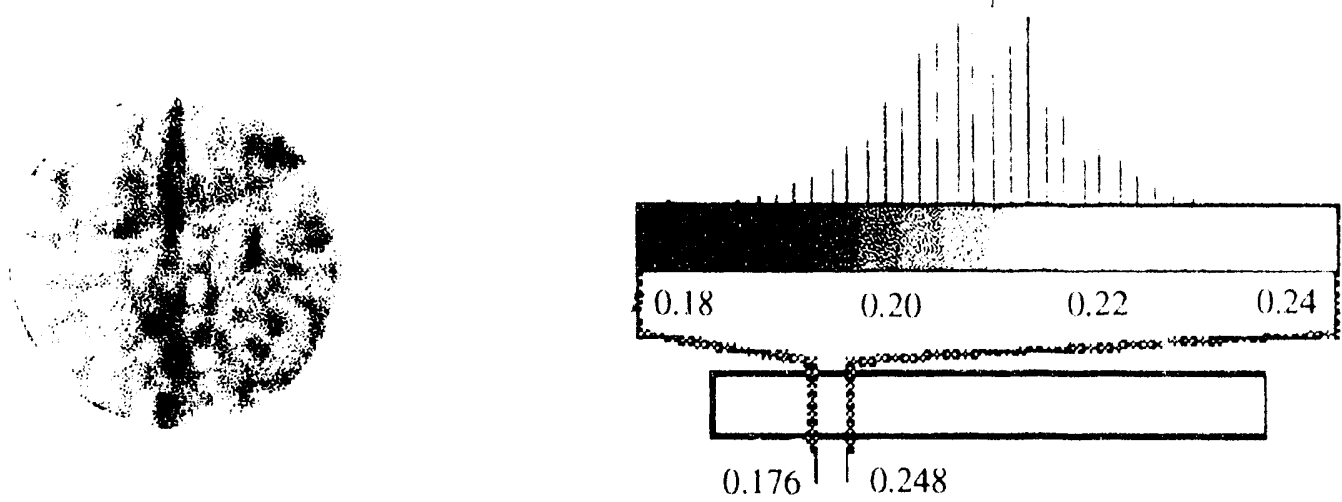

FIGURE 2. - Comparison of CT density scale and porosity scale for the same CT image from coreflood CT-CF 3. 
Inlet

Direction of flow $\rightarrow \quad$ Tracer $\downarrow$
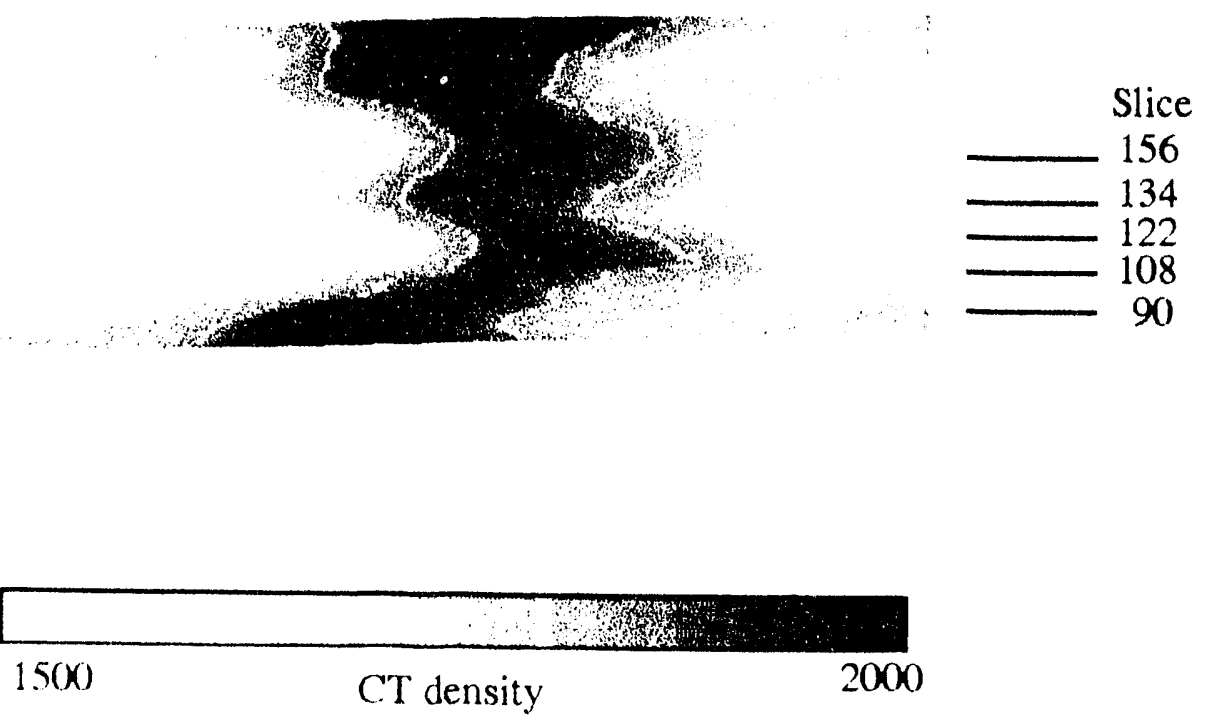

FI(YURE 3. - Composite CT image oriented in thi vertical direction along core for tracer test, CT-CF 4. Non uniformı fluid advance can be observed. Slice number refers to position of slices shown in Fig. 5 and oriented perpendicularly to this slice.

This and following CT images are reproduced using a 256-shade gray scale. The images have been artificially enhanced by removing shading in some areas to emphasize differences in CT density between the tracer slug and the brine used to saturate the core. 
Inlet

Direction of flow $\rightarrow$

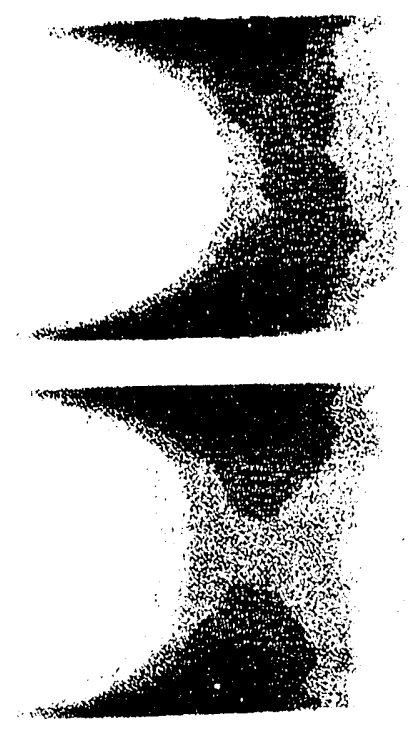

Slice 156

Slice 134

Slice 122

Slice 108

Slice 90

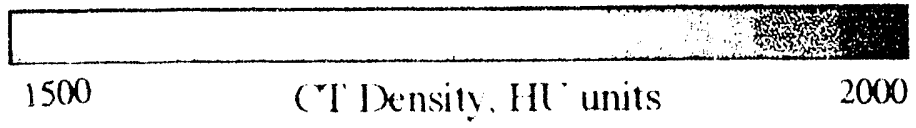

FIGURE 4 - Composite CT images oriented in the horizontal direction for tracer test, CT-CF 4. Slice numbers correspond to those sited in Fig. 3. Fluid advance is more uniform within a bedding layer. These layers are oriented in the horizontal direction for this core. 
Inlet

Direction of flow $\rightarrow$

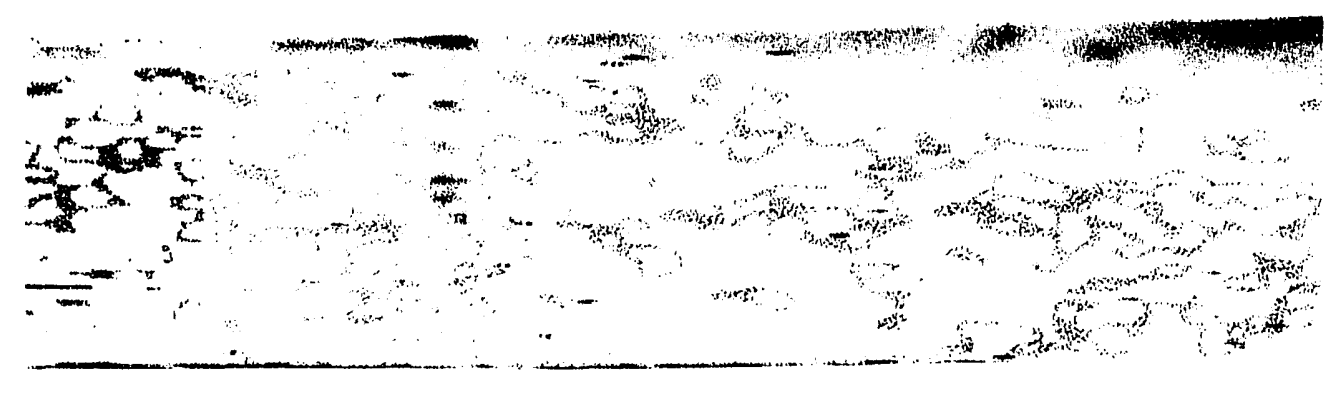

CT-CF 1

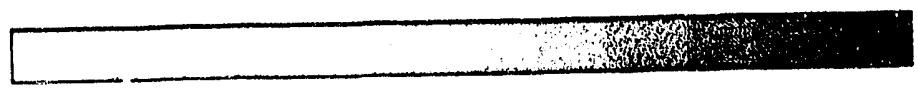

$0 \% \quad$ Oil saturation $\quad 50 \%$

CT-CF 4

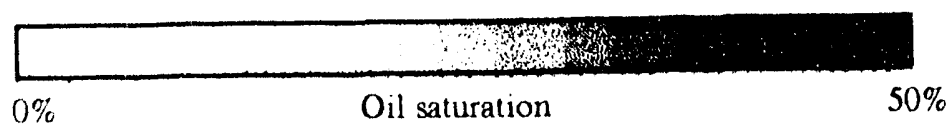

FIGURE 6. - CT images after polymer injection for CT-CF 1 and CT-CF 4. Both tests show very low oil saturations after completion of fluid injection. 
Inlet

Direction of flow $\rightarrow$

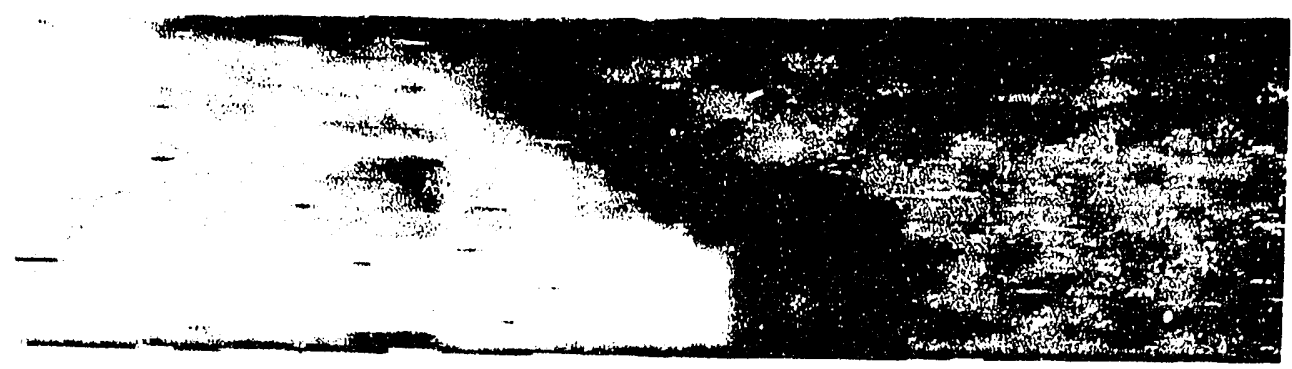

CT-CF 1
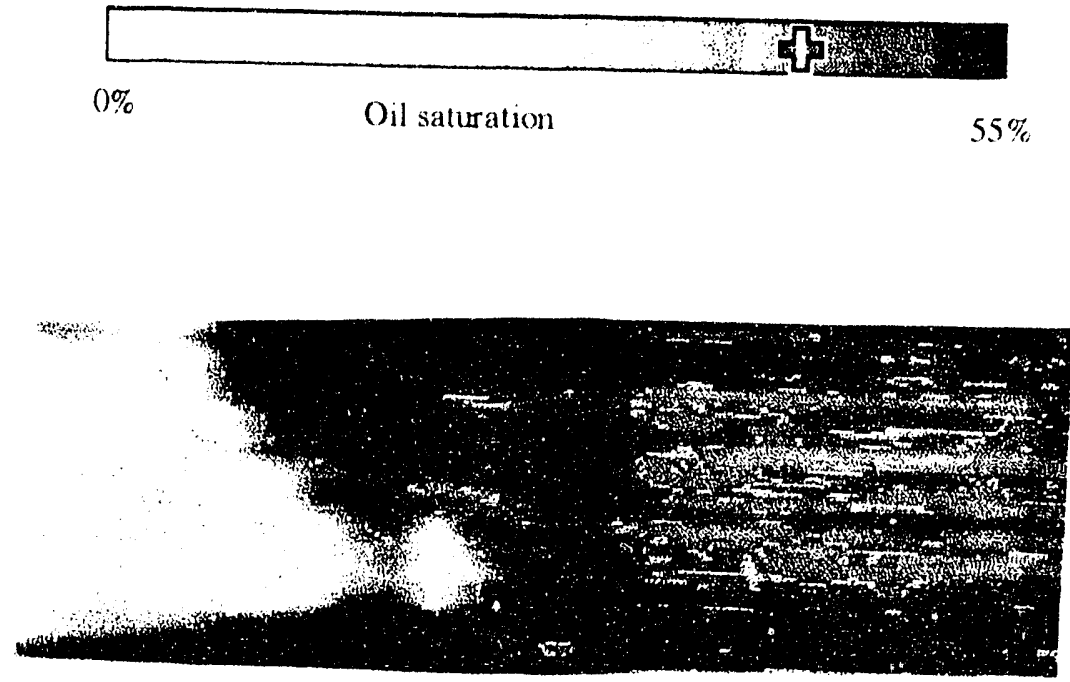

CT-CF 4

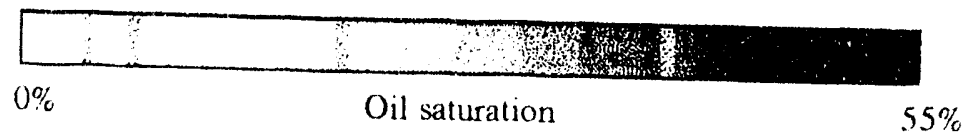

FIGURE 5. -CT images after surfactant injection for CT-CF 1 and CT-CF 4 (vertical orientation). Both tests show non uniform fluid advance. 


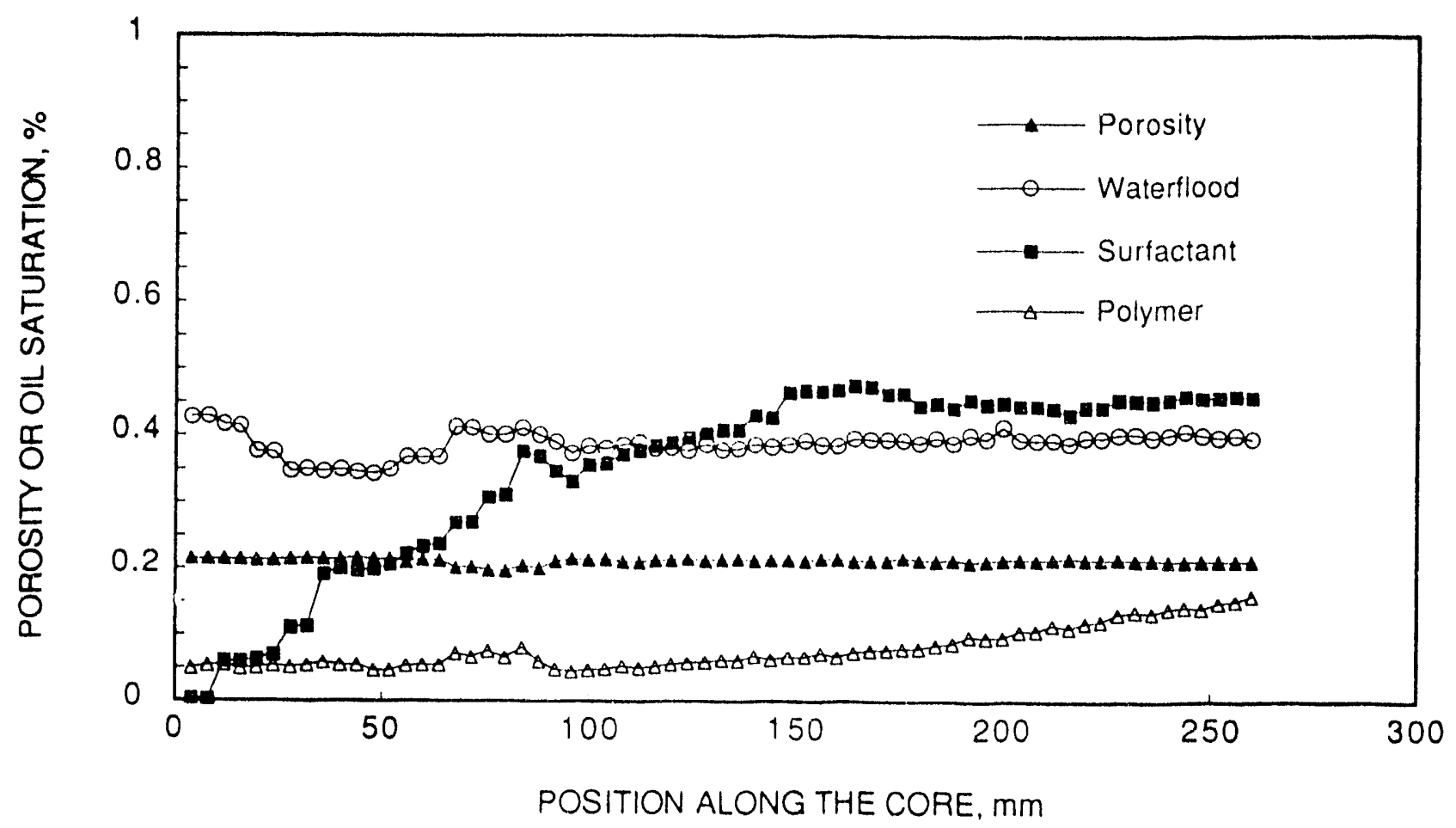

FIGURE 7. - Average oil saturation distributions for each CT slice after waterflood, surfactant injection, and polymer injection for CT-CF 1.

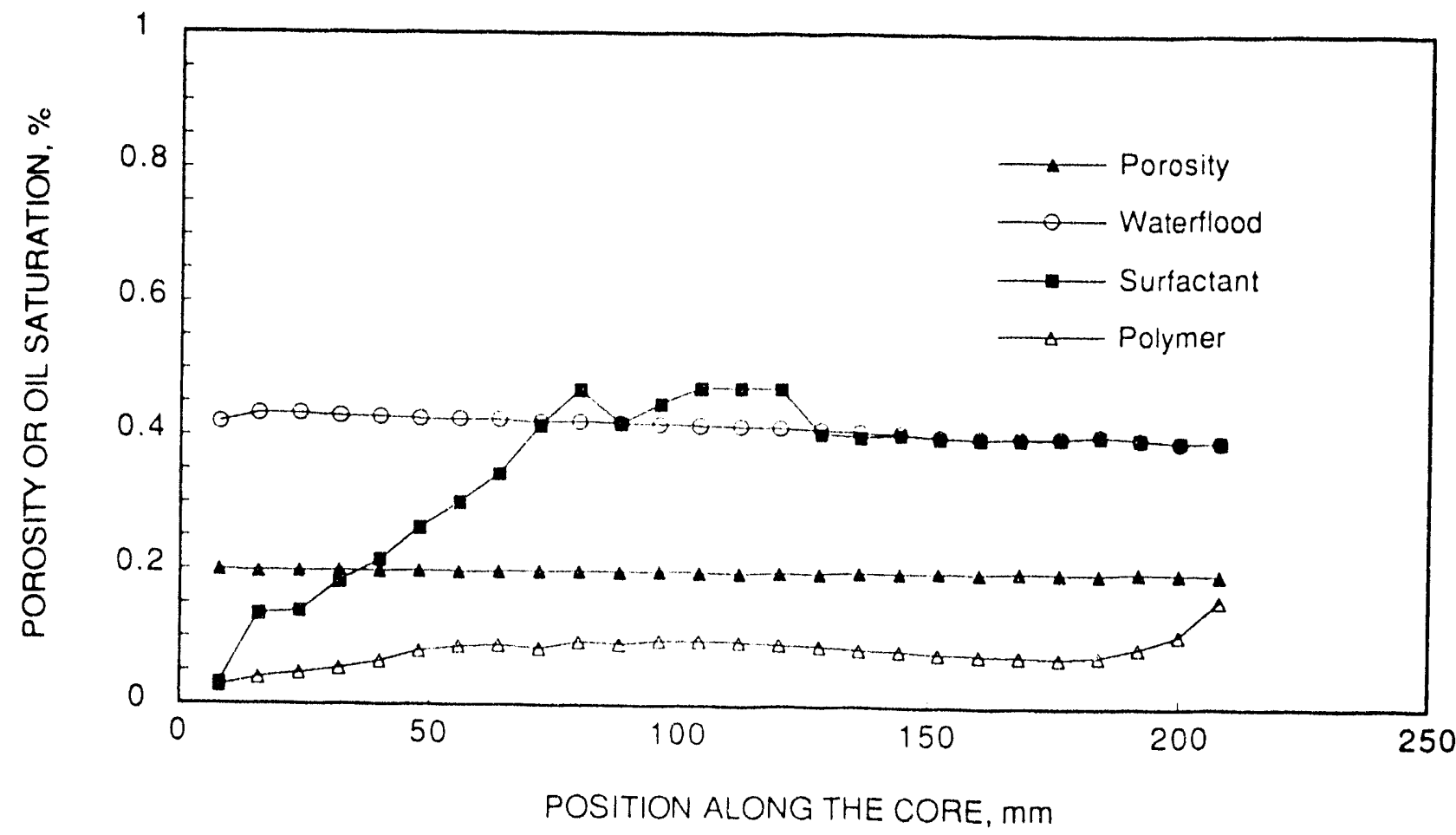

FIGUKE 8. - A verage oil saturation distributions for each CT slice after waterfood, surfactant injection, and polymer injection for CT-CF 4. 


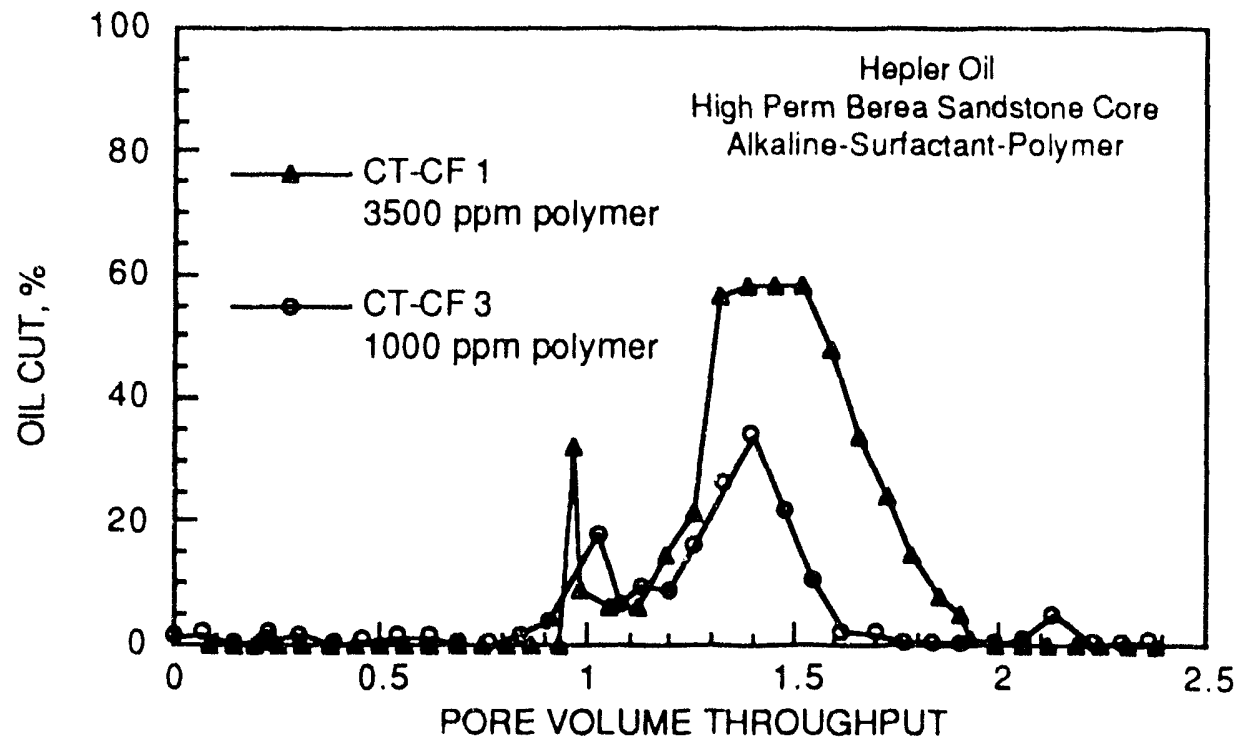

FIGURE 9. - Comparison of oil production histories for CT-CF 1 and CT-CF 3. The effect of lower concentration mobility control polymer can be observed in reduced oil production after polymer injection. 
Irilet

Direction of flow $\rightarrow$

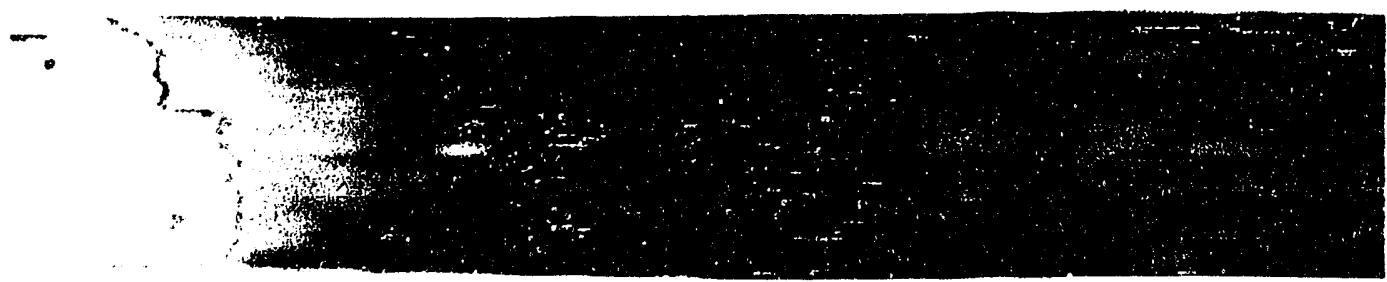

After surfactant injection

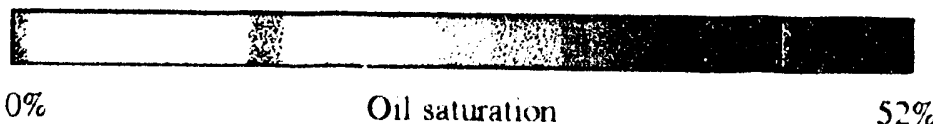

$52 \%$

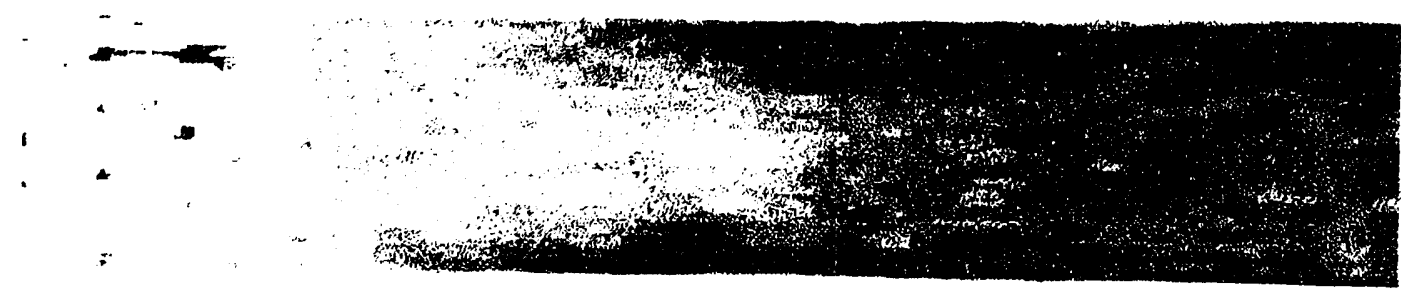

After polymer injection

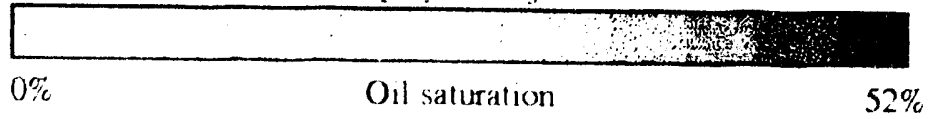

FIGURE 10. - Composite CT images of CT.CF 3 after surfactant injection and polymer injection (vertical orientation). 


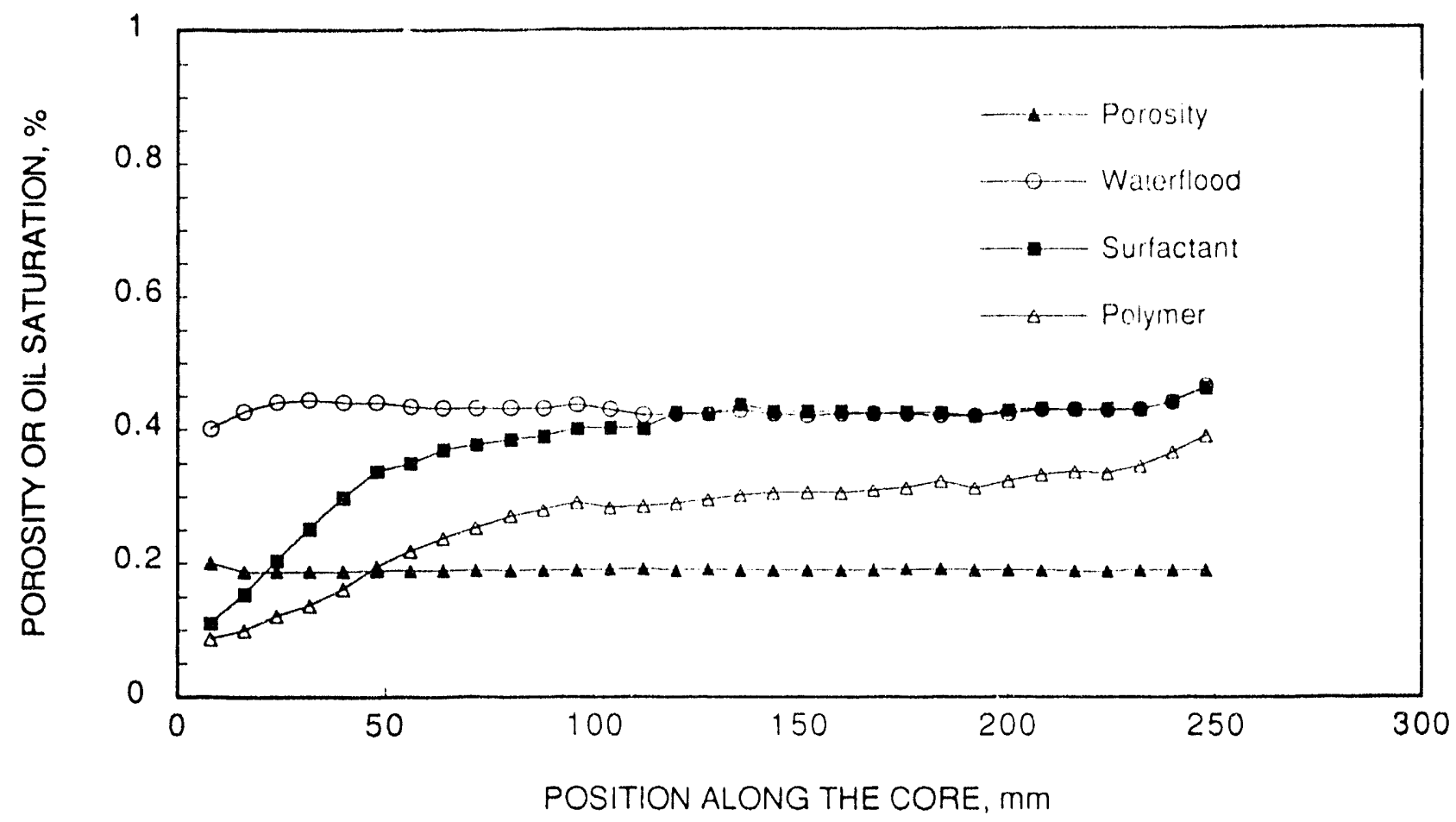

FIGURE 11-a. - Average oil saturation distributions after waterflood, surfactant injection and polymer injection for CT-CF 3.

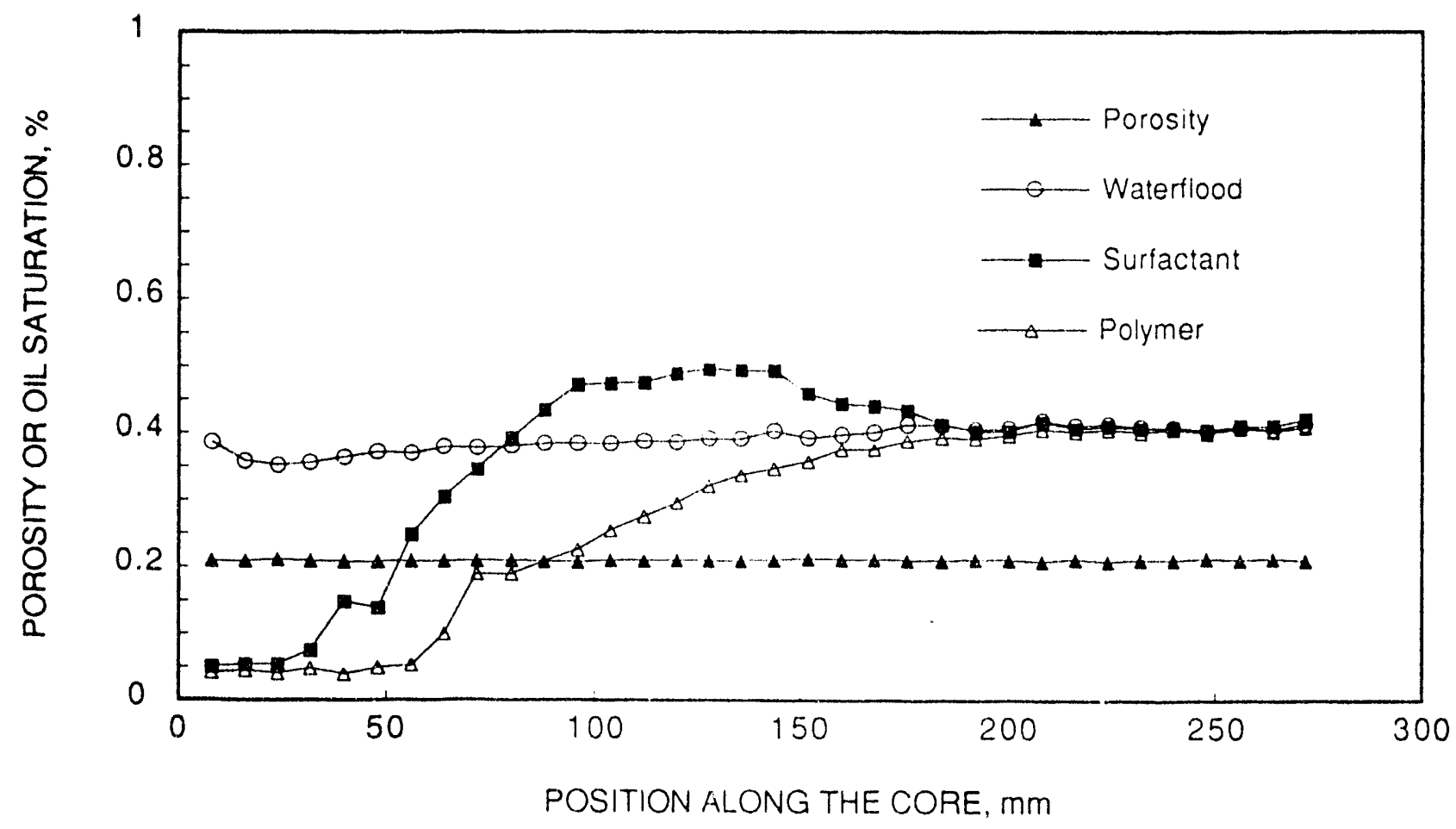

FIGURE 11-b. - Average oil saturation distributions after waterflood, surfactant injection and polymer injection for CT-CF 2. 


\section{Inlet}

Direction of now $\rightarrow$

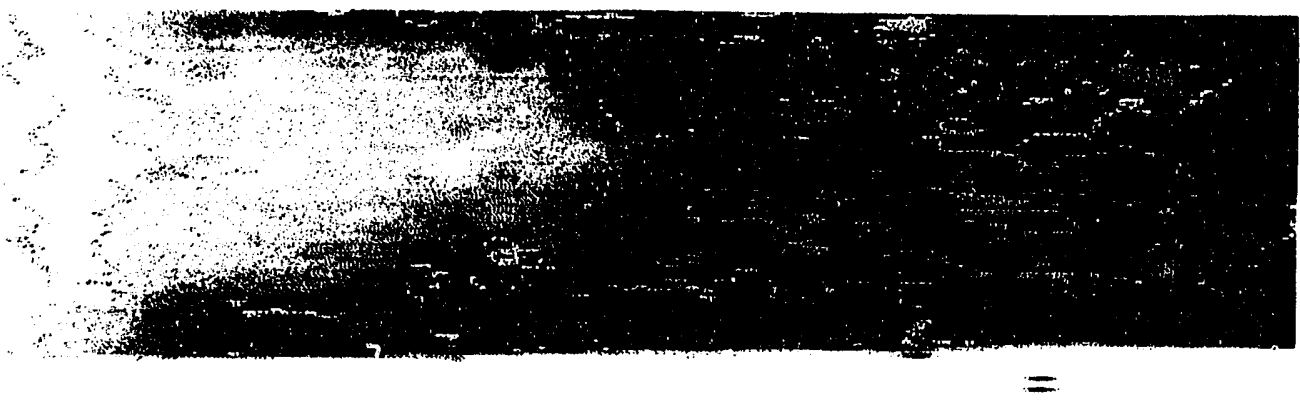

After surfactant injection
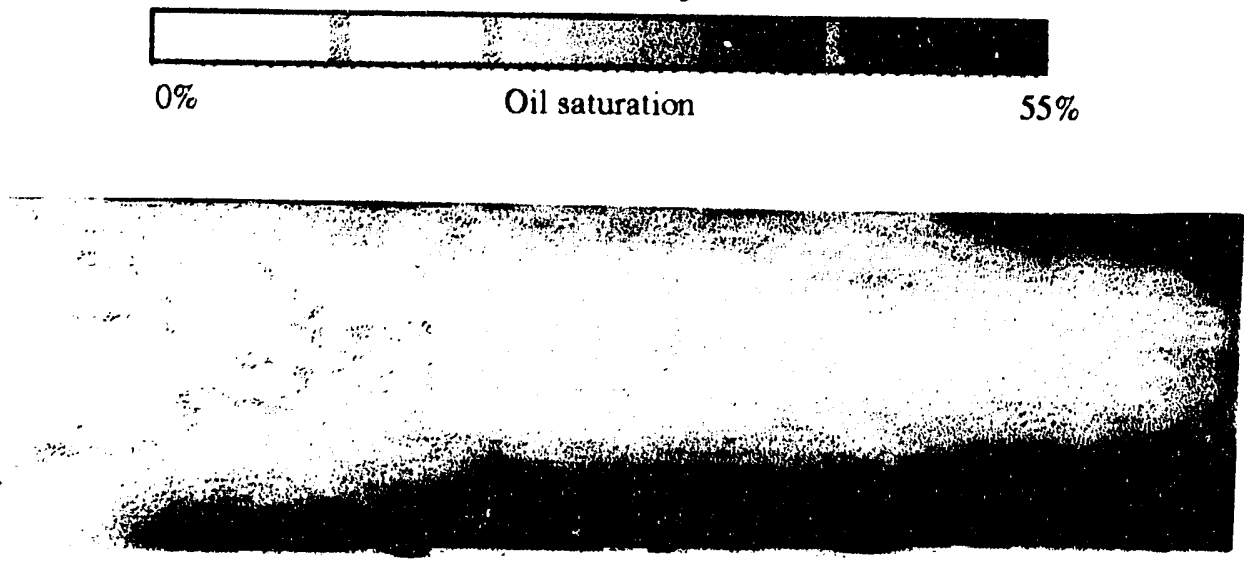

After polymer injection

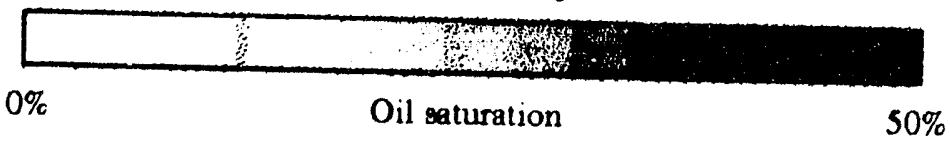

\section{FIGURE 12. - Composite CT images of CT-CF 2 after surfactant injection and polymer injection.}




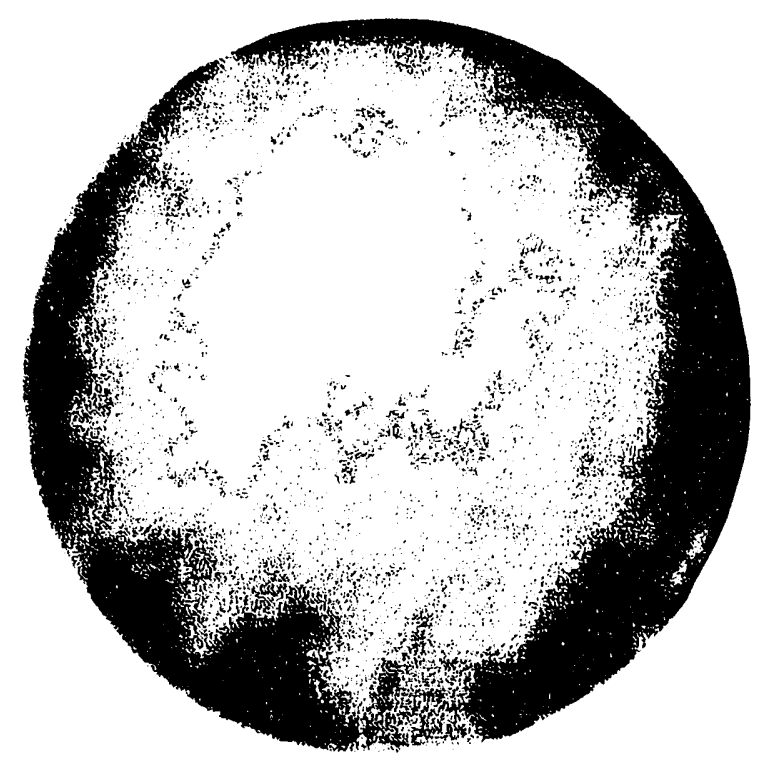

Oil Saturation

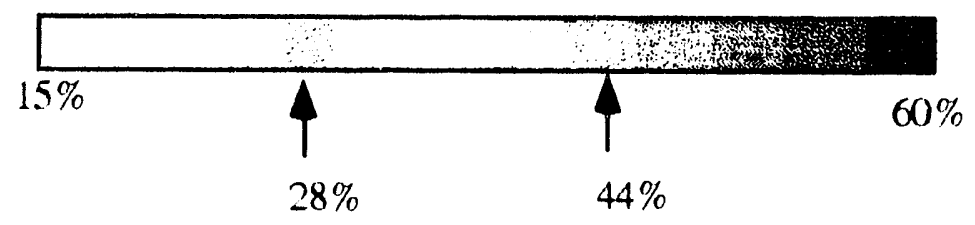

FIGURE 13. - CT image of oil saturation distributions for a core cross section approximately $3 \mathrm{~cm}$ from the core exit for CT-CF 2. 

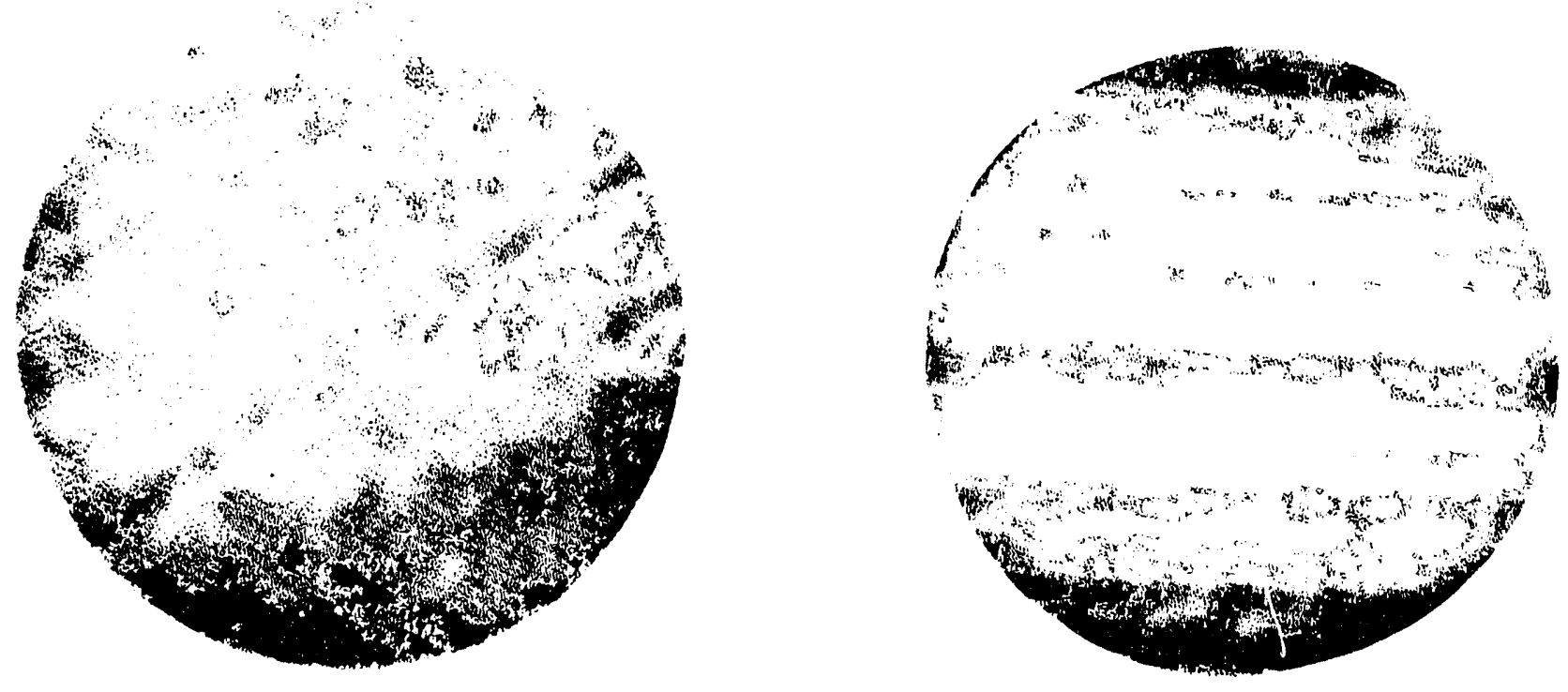

FIGURE 14. Comparison of CT images of oil saturation distributions approximately 1 to $1.8 \mathrm{~cm}$ from the core entrance for CT-CF 2 and CT. CF 4.

*U.S.GPO: 1992-761-027/60060 

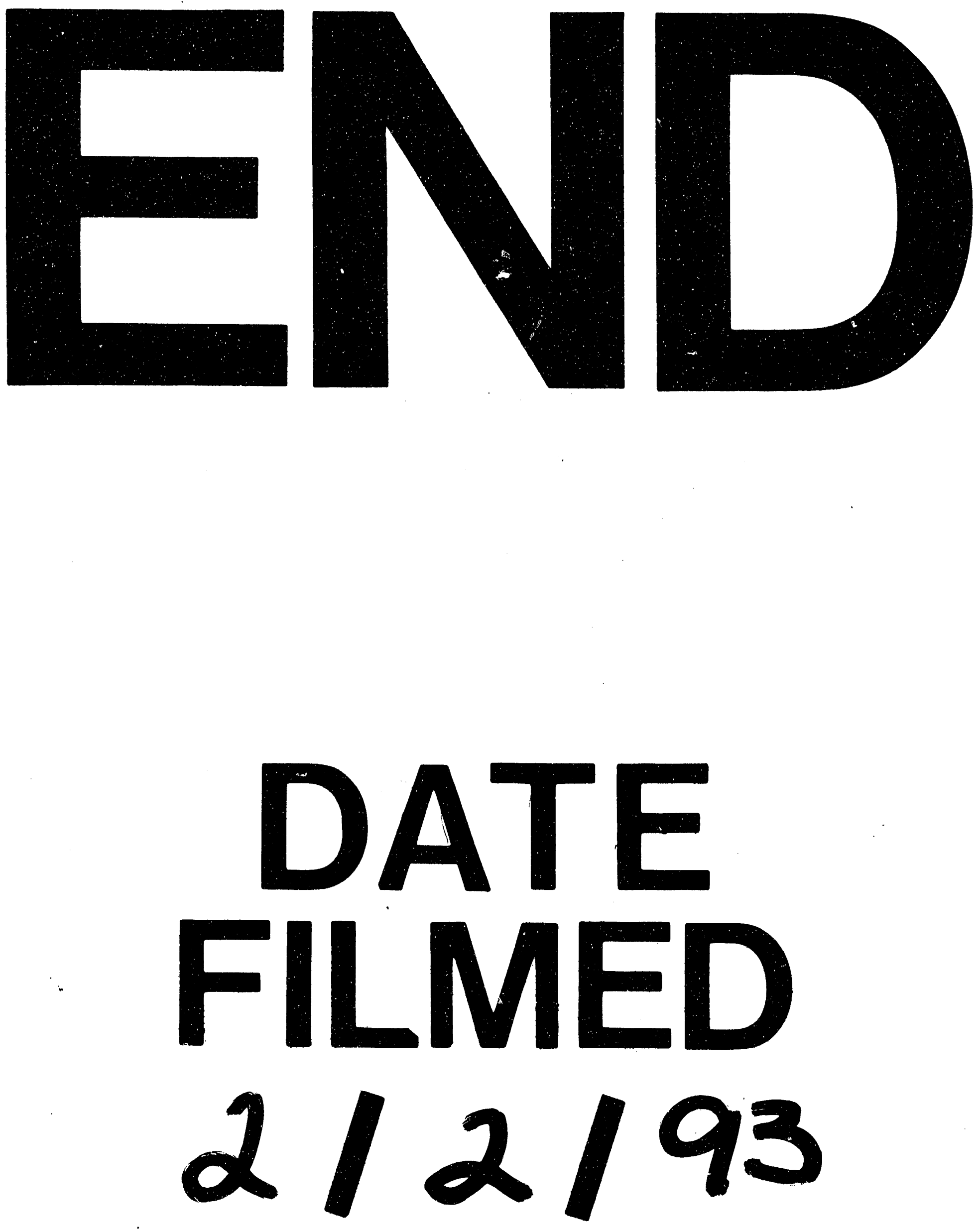

1 
